\title{
Analysis of selected allergens present in alcohol-based perfumes
}

\begin{tabular}{l} 
C H R O N I C L E \\
\hline Article history: \\
Received February 18, 2021 \\
Received in revised form \\
April 25, 2021 \\
Accepted May 7, 2021 \\
Available online \\
May 7, 2021 \\
\hline Keywords: \\
Perfumery products \\
Fragrance substances \\
Allergens \\
IFRA Standards \\
Gas chromatography
\end{tabular}

Anna Lętocha ${ }^{a^{*}}$ and Rafał Rachwalik ${ }^{a}$

${ }^{a}$ Faculty of Chemical Engineering and Technology, Cracow University of Technology, Warszawska 24, 31-155 Kraków, Poland

\section{A B S T R A C T}

The aim of the research was to analyse fragrance allergens in selected alcohol-based perfumery products with the application of gas chromatography. Toilet waters and scented waters were analysed. Samples of the selected perfumery products were tested for the presence of typical allergens, such as linalool, citral, citronellol, geraniol, eugenol and alpha-isomethyl ionone, in the so-called fragrance concentrate. The obtained results showed that each of the products contained at least a few of the above-mentioned allergens. Nevertheless, the majority of the analysed products satisfied the recommendations of the Scientific Committee on Cosmetic Products and Non-food Products valid for cosmetics intended to remain on the skin for some time.

(c) 2021 Growing Science Ltd. All rights reserved.

\section{Introduction}

Depending on the content of the fragrance composition and ethyl alcohol, perfumery products can be divided into: parfum (perfume), eau de parfum (scented water), eau de toilette (toilet water), eau de Cologne (cologne) and eau de fraiche (body splash, body spray, body mist or body spritz). ${ }^{1,2}$ In accordance with this classification, scented waters may contain 10-20\% of fragrance concentrate dissolved in $80-90 \%$ ethanol (typically this is around 15\%). The fragrance usually lasts 4-6 hours, and these waters are mainly used during the day. In turn, toilet waters may contain $5-15 \%$ of fragrance concentrate dissolved in $60-85 \%$ ethanol (typically this is around 10\%). In the case of this range of products, products for men contain a lower concentration of fragrance concentrate (around 5\%). ${ }^{3-5}$

In 2009 fragrance allergens (26 compounds) were included in the list of substances which may be used as ingredients in cosmetic products exclusively on condition that specific restrictions are respected (Annex III). At present this list is undergoing the process of being expanded to 82 compounds. ${ }^{6}$

\subsection{Characteristics of the tested allergens}

Annex III to the EU regulation 1223/2009 currently includes the following fragrance substances (names in accordance with the INCI): amyl cinnamal, benzyl alcohol, cinnamyl alcohol, citral, eugenol, hydroxycitronellal, isoeugenol, amylcinnamyl alcohol, benzyl salicylate, cinnamal,

* Corresponding author.

E-mail address: anna.letocha@doktorant.pk.edu.pl (A. Łętocha)

(c) 2021 Growing Science Ltd. All rights reserved. doi: $10.5267 /$ j.ccl.2021.5.001 
coumarin, geraniol, hydroxyisohexyl 3-cyclohexene carboxaldehyde, anise alcohol, benzyl cinnamate, farnesol, butylphenyl methylpropional, linalool, benzyl benzoate, citronellol, hexyl cinnamal, limonene, methyl 2-octynoate, alpha-isomethyl ionone, Evernia prunastri extract, Evernia furfuracea extract. ${ }^{6,7}$ The maximum level of application on the skin of the analysed compounds for products belonging to category 4 , which contains all kinds of perfumery products, is defined by the International Fragrance Association (IFRA) Standards. ${ }^{8}$ However, in accordance with the recommendation of the Scientific Committee on Cosmetic Products and Non-food Products, in the case of cosmetic products intended to remain on the skin for some time, if the content of the fragrance substance

a final product exceeds the concentration of $0.001 \%$, its presence must be specified on the product label. ${ }^{7,9-11}$

The research covered selected groups of alcohol-based perfumery products: scented waters (eau de parfum) and toilet waters (eau de toilette) for the content of the six out of 26 allergens: linalool, citral, citronellol, geraniol, eugenol and alpha-isomethyl ionone.<smiles>C=CC(C)(O)CCC=C(C)C</smiles><smiles>CC(C)=CCCC(C)=CCO</smiles><smiles>CC(C)=CCCC(C)=CC=O</smiles><smiles>CC(C)=CCCC(C)=CC=O</smiles>
citral (geranial and neral)<smiles>C=CCc1ccc(O)c(OC)c1</smiles>

eugenol<smiles>CC(C)=CCCC(C)CCO</smiles>

citronellol<smiles>CC(=O)/C(C)=C/C1C(C)=CCCC1(C)C</smiles>

alpha-isomethyl ionone

Fig. 1. Structural formulas of tested allergens.

\subsection{Linalool}

Linalool, i.e. 3,7-dimethyl-1,6-octadien-3-ol (Fig. 1), is an unsaturated secondary alcohol with the characteristic scent of lily of the valley. Its high quantities are present in lavender, coriandrum, rose and thyme oils, frequently in the ester form as linalyl acetate. ${ }^{4}$ It constitutes an ingredient of numerous fragrance compounds. It may be found in fragrances used in: decorative cosmetics, delicate scents in perfumery products, shampoos, toilet soaps and other toiletries, as well as in non-cosmetic products, such as household cleaning products and detergents. The maximum content of application on the skin in products with a delicate fragrance amounts to $4.3 \%$ assuming that the applied fragrance oil constitutes up to $20 \%$ of the final product. ${ }^{12-14}$

\subsection{Citral}

Citral, or 3,7-dimethyl-2,6-octadienal, is an unsaturated terpene aldehyde with a characteristic strong lemon scent. This compound is present in nature in the form of two isomers: geranial and neral (Fig. 1). The mass ratio of the two isomers is dependent on a plant raw material in which it is present, 
but typically it is in the range of 40:60 or 60:40. Geranial has an intensive lemon scent, whereas neral has a more delicate scent. The most valuable source of citral is oil of the following plants: lemon myrtle, Litsea cubeba and lemongrass. It is also present in many citrus fruits in varying quantities. Citral is widely used in fragrance preparations and constitutes an ingredient of numerous consumer products. It is commonly used in the perfume and cosmetic industries. ${ }^{4}, 15$ The maximum content of citral applied on the skin is defined by the International Fragrance Association (IFRA) Standards. ${ }^{16}$ The recently updated list of standards is based on a quantitative risk assessment for skin sensitization. As a result of the approach based on the concept of the quantitative risk assessment (QRA), in the case of citral the values cannot go beyond the range $0.04-5.0 \%$. In the case of category 4 , which contains perfumery products, the maximum level of the application of this compound amounts to $0.6 \% .^{16,17}$

\subsection{Citronellol}

Citronellol, or 3,7-dimethyloct-6-en-1-ol (Fig. 1), is an unsaturated primary alcohol. It may occur in the form of two isomers: (R)-citronellol and (S)-citronellol. Both compounds are present in essential oils of lemon-scented boronia, Pelargonium geranium, rose, lemon-scented eucalyptus, clary sage and sandalwood tree. ${ }^{4,15}$ Citronellol is an aromatic ingredient commonly used in perfumery and cosmetic products. It is present in floral compositions with a fresh rose fragrance lasting longer than 48 hours. The maximum level of citronellol application on the skin is defined by the IFRA Standards. ${ }^{18}$ In accordance with the QRA approach and the resulting restrictions, in the case of citronellol the usage values cannot go beyond the range $0.08-13.3 \%$. In the case of category 4 , which contains among others perfumery products, the maximum content of citronellol application amounts to $12 \% .^{18,19}$

\subsection{Geraniol}

Geraniol, or 3,7-dimethyl-2,6-octadien-1-ol (Fig. 1), is a monoterpene alcohol. Two isomers are distinguished: geraniol and nerol. Geraniol has an odour similar to that of pelargonium, whereas nerol is characterised by a rose-orange scent. ${ }^{4,}{ }^{15}$ Geraniol is a fragrance ingredient very commonly used in all kinds of floral aromatic compositions. It is used in products such as: toilet soaps, shampoos, intimate care products, household chemicals as well as perfumery products. In the case of perfumery products, geraniol constitutes a top note component. ${ }^{15,} 20$ The maximum content of geraniol application on the skin defined by the IFRA Standards fits within the range $0.3-8.6 \% .{ }^{21} \mathrm{In}$ accordance with the quantitative risk assessment approach, in the case of category 4 the maximum content of geraniol application amounts to $4.7 \% .^{20,21}$

\subsection{Eugenol}

Eugenol, or 2-methoxy-4-allylphenol or 2-methoxy-4-(2-propenyl)phenol (Fig. 1), is an organic terpene compound with an ether structure. It constitutes the principal extracted component in cloves and is responsible for their characteristic odour. It is also present in nutmeg, cinnamon, basil and bay laurel leaves. ${ }^{4,22}$ Eugenol is a fragrance ingredient used in the perfume industry, and may be used as a substitute for clove oil. It is applied both in perfumery and other cosmetic products (soaps, skin care products). ${ }^{22,23}$ The maximum level of eugenol application on the skin defined by the IFRA Standards fits within the range $0.2-4.3 \% .{ }^{24}$ In accordance with the QRA approach, in the case of category 4 the maximum content of eugenol application amounts to $2.5 \% .^{22,24}$

\subsection{Alpha-isomethyl ionone}

Alpha-isomethyl ionone, or 3-methyl-4-(2,6,6-trimethylcyclohex-2-en-1-yl)but-3-en-2-one (Fig. 1 ), is an ingredient used in numerous fragrance compounds. Alpha-isomethyl ionone may be found in floral compositions of perfumery products, cosmetics (shampoos, toilet soaps, balms, creams) as well 
as in household chemicals (household cleaning products and detergents). The maximum content of alpha-isomethyl ionone application on the skin for products with a delicate scent amounts to 3.69\%, assuming that the concentration of the applied fragrance oil in a final product is up to $20 \%{ }^{25}$

\section{Results and discussion}

The analysis covered 50 samples of alcohol-based perfumery products belonging to scented and toilet waters intended for both women and men. Their composition was analysed for the content of such compounds as: linalool, citral, citronellol, geraniol, eugenol and alpha-isomethyl ionone. Each of the tested samples had information on the label concerning fragrance substances, among allergens, present in a given product. Fig. 2 illustrates an example of a chromatogram representing scented water for men Armani Idole. Retention times for particular compounds were as follows: linalool - 6 min, citral, taking into account citral A (geranial) - around $15.5 \mathrm{~min}$ and citral B (neral) - around $13.5 \mathrm{~min}$, citronellol - around $14 \mathrm{~min}$, geraniol - around $15.5 \mathrm{~min}$, eugenol - around $19 \mathrm{~min}$ and alphaisomethyl ionone - around $23 \mathrm{~min}$.

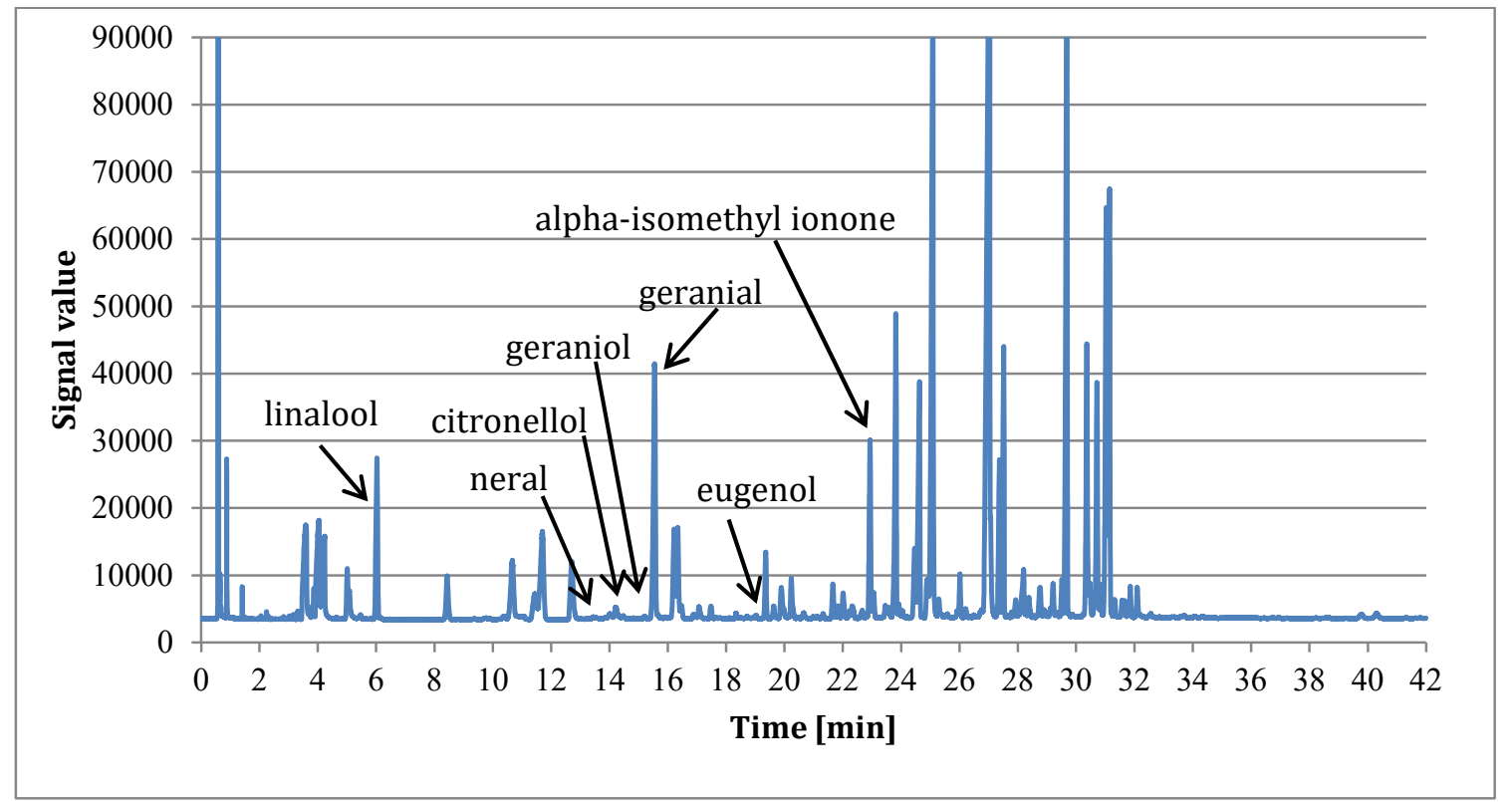

Fig.2. Chromatogram for scented water for men Armani Idole.

In the case of toilet waters, the content of the fragrance concentrate is within the range $5-15 \%$. However, in scented waters the content amounts to $10-20 \%{ }^{3,4}$ On the basis of the results of the chromatographic analysis the content of particular compounds in the tested products was calculated. At the same time, it was verified whether the information placed on a cosmetic packaging complied with applicable regulations, i.e., whether in the case of exceeding the concentration of $0.001 \%$, the information on a cosmetic label confirms the presence of the compound. ${ }^{7,9-11}$

Fig. 3 illustrates the percentage content of the tested allergens in the fragrance concentrate of toilet waters for women. The data presented in the figure make it possible to notice that the presence of at least a few analysed substances was identified in all the samples. The samples of Moschino Cheap\&Chic Hippy Fizz Woman were characterized by the highest total content of allergens, and Avon scent essence sparkly citrus demonstrated a slightly lower content. The lowest amount of the tested substances is present in the fragrance concentrate of the water Mexx Black Woman. In the case of toilet waters for women, linalool is the most common compound and the one present in the highest concentrations. This may result from the fact that the compound is characterized by a fresh delicate scent imparting the lavender or bergamot fragrance to perfume products. Citronellol is another 
popular compound frequently present in toilet waters for women, but its concentrations are low. Similarly to linalool, it enriches the product fragrance with a floral note.

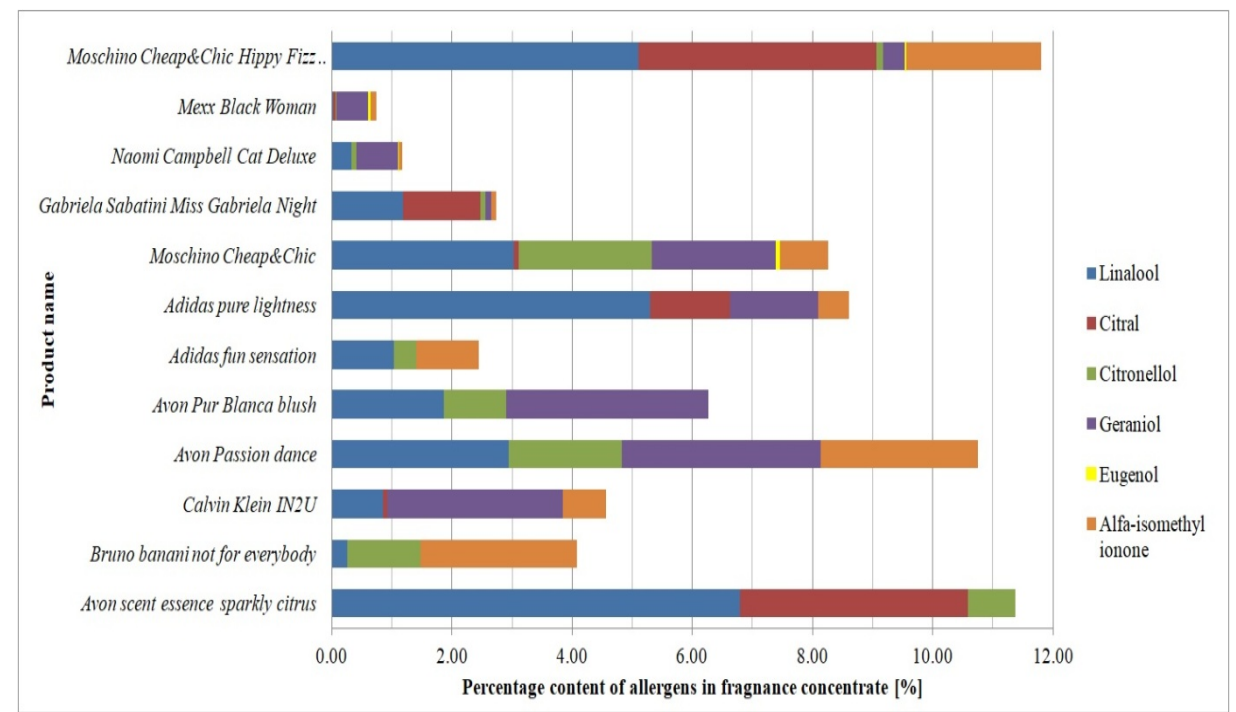

Fig. 3. Graph illustrating the percentage content of allergens in fragrance concentrate in toilet waters for women

As far as toilet waters for men are concerned, the sample with Davidoff coolwater was characterized by the highest content of the analysed allergens in the fragrance concentrate (Fig.4). However, the lowest content of the compounds may be observed in the sample of Calvin Klein Obsession Night. Analysing the data presented in Fig. 4 it can be noticed that linalool, geraniol and citral are the compounds present in the highest concentrations. The presence of the last allergen mentioned may indicate that it is in products for men that citrus notes are more frequently used.

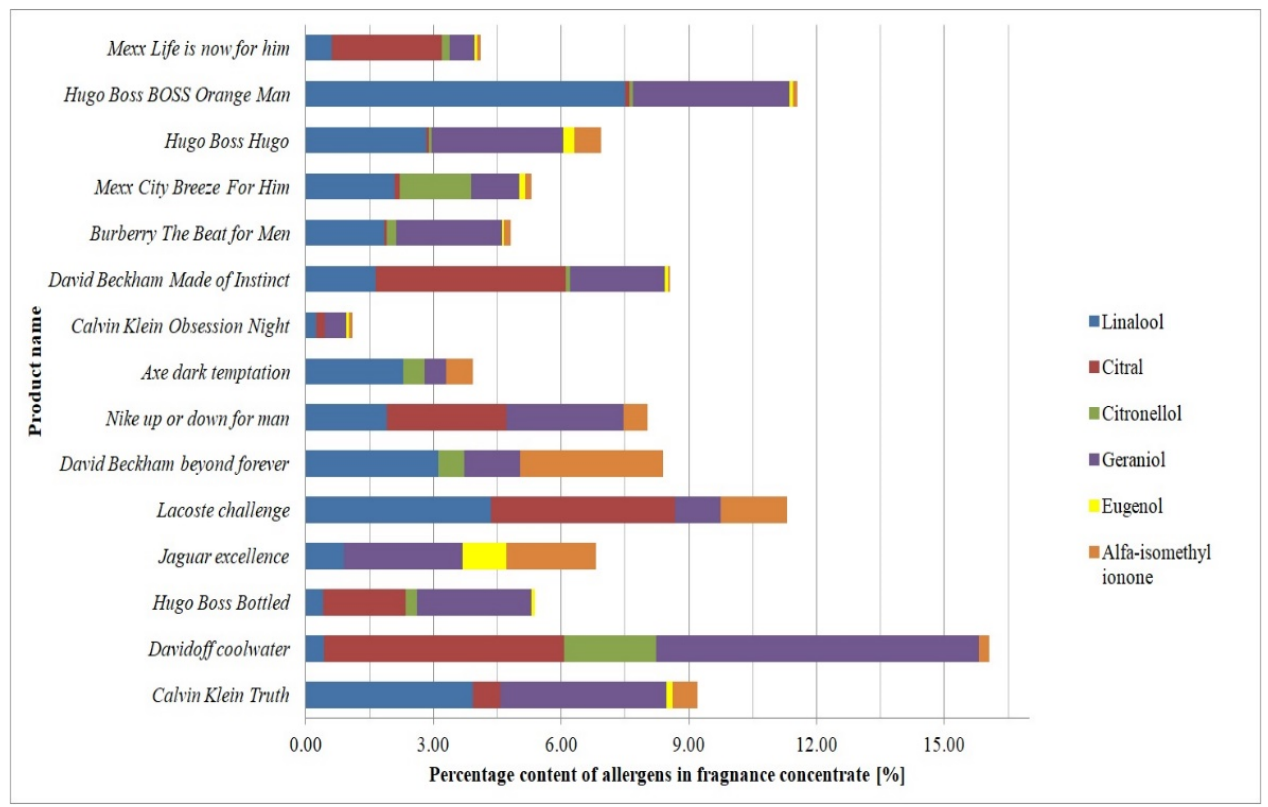

Fig. 4. Graph illustrating the percentage content of allergens in fragrance concentrate in toilet waters for men.

Comparing the results obtained for toilet waters for women and men it may be concluded that the samples satisfy the recommendations of the Scientific Committee on Cosmetic Products and Nonfood Products specified for cosmetic products intended to remain on the skin for some time, according to which the presence of a fragrance in the final product must be mentioned on a product 
label if its concentration of $0.001 \%$ is exceeded. Comparing allergens present in the fragrance concentrate in toilet waters it may be concluded that in the products for both women and men linalool is the compound present in all of the samples. It is present in perfumery products enriching them with a lavender or bergamot odour. Taking into account toilet waters for women and men it may be noticed that they are characterized by a similar content of this compound. This may indicate that in the products for both women and men there are floral and citrus accents, which are typical for the substance.

In the case of citral it may be noticed that products for men are characterized by its higher content. This may indicate that in products for men citrus or fruity notes, which give their products an intensive scent, are used more frequently. A similar dependence may be seen with respect to geraniol and eugenol. However, as far as citronellol is concerned, its presence is more frequent in products for women. This may result from the fact that this compound is characterized by a rose fragrance, which is more distinctive in products for women. As for the presence of alpha-isomethyl ionone in samples of toilet waters for women and men, it may be noticed that these products are characterized by a similar content of this compound.

Fig. 5 illustrates the content of the tested allergens in the fragrance concentrate of selected scented waters for women. As in the case of toilet waters, the presence of at least a few of the analysed substances was observed in all the samples. Definitely the highest total content of allergens may be observed in the case of the sample Calvin Klein Eternity moment. The lowest content of the analysed substances is present in the samples Calvin Klein deep euphoria and Bi-es Experience the magic. Linalool and geraniol are the most frequently present compounds in the case of scented waters for women. Alpha-isomethyl ionone, however, is present more seldom but its high concentrations were observed.

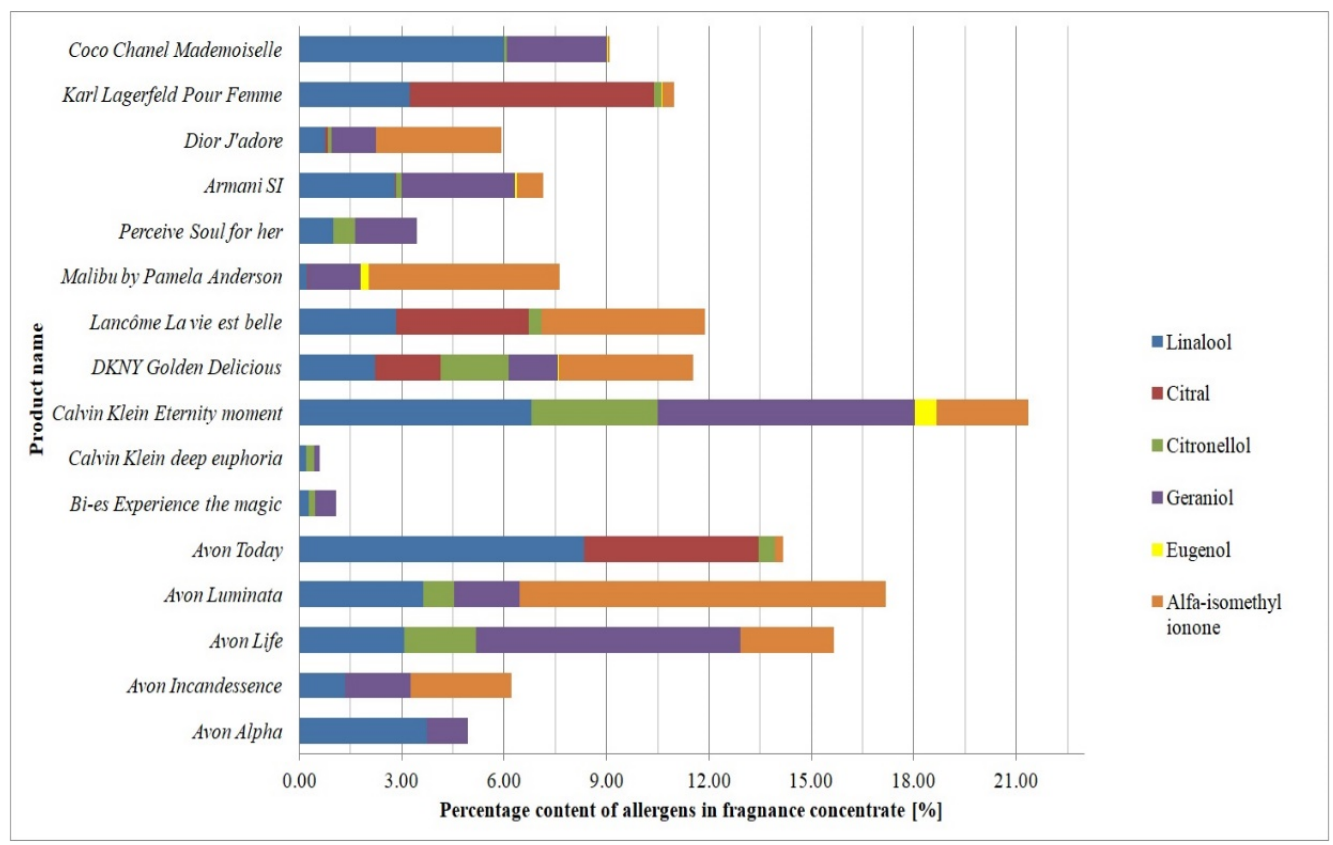

Fig. 5. Graph illustrating the percentage content of allergens in fragrance concentrate in scented waters for women.

In the case of the analysis of fragrance concentrate in scented waters for men (Fig. 6), the highest content of the tested allergens was identified in the sample with the water Dolce\&Gabbana Intenso. On the other hand, the sample Amouge Memoir Man had the lowest concentration of the analysed 
compounds. Studying the data presented in Fig. 6, it may be observed that linalool, geraniol and alpha-isomethyl ionone are the most abundant compounds.

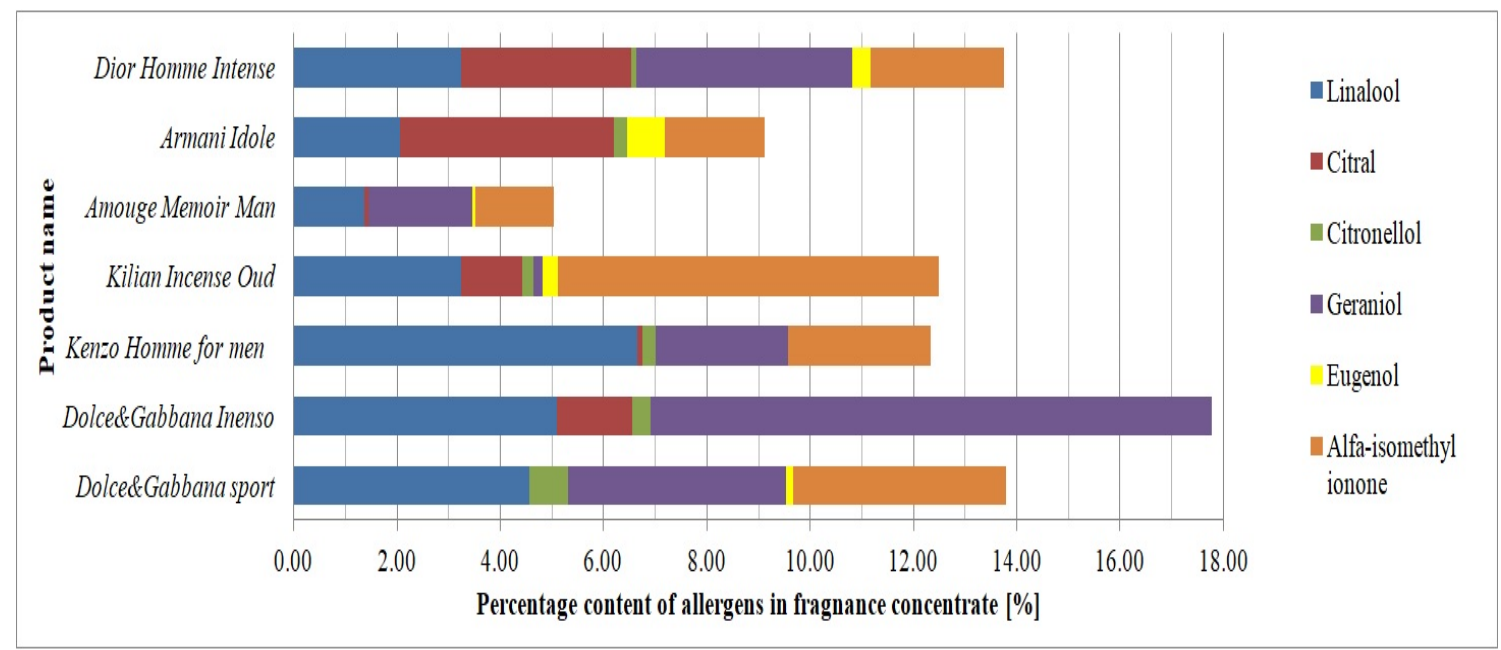

Fig. 6. Graph illustrating the percentage content of allergens in fragrance concentrate in scented waters for men.

Comparing the results obtained for scented waters for women and men it may be concluded that they contain the tested substances in fragrance concentrate in different amounts depending on a particular product. In the case of scented waters all of the samples also satisfy the recommendations of the Scientific Committee on Cosmetic Products and Non-food Products for cosmetics intended to remain on the skin for some time. In the case of some perfumery products which, however, do not exceed the value recommended by the SCCNFP, appropriate information appears in a product content section (e.g. the Armani Idole sample tested with respect to geraniol). Similar dependencies as in the case of toilet waters may be observed with respect to the tested compounds in fragrance concentrate of scented waters. The compound that was present in all samples was linalool. This is undoubtedly due to its fresh and mild scent containing a citrus note. Citral, geraniol and eugenol are more often present in products for men, whereas citronellol in products for women. Taking into account the presence of citral in the fragrance concentrate of perfumery products (of both toilet waters and scented waters), in more than $1 / 3$ of the tested samples the presence of this compound was not recorded. This may be due to its intensive lemon fragrance, which is difficult to compose. The more frequent presence of geraniol in products for men may be associated with a pelargonium scent, which is characteristic of this compound. It constitutes the floral accent, typical for products for men, and represents mainly the top note component of the perfumery product.

A similar situation takes place with respect to eugenol, whose presence was not identified in approximately a half of the tested samples. These are mostly products for women, both toilet waters and scented waters. This is most certainly determined by the fact that eugenol is present in spices such as: nutmeg, cinnamon, basil or bay laurel leaves, and its fragrance resembles that of cloves. On the other hand, aromatic notes, which give an intensive spicy fragrance to products, are much more often used in products for men. However, taking into account the presence of citronellol in the fragrance concentrate of perfumery products, with respect to many products the level of this compound is very low, but its presence was noted in the majority of samples. Nevertheless, it is the products for women that are characterized by a higher content of citronellol. This probably results from the fact that floral notes - in this case the long-lasting rose fragrance - are used in products for women significantly more often. Analysing the presence of alpha-isomethyl ionone in the samples with toilet waters and scented waters, it may be stated that the compound is very frequently used for different groups of perfumery products. Comparing scented waters for women and scented waters for 
men it may be concluded that, as in the case of toilet waters, the application of alpha-isomethyl ionone is at a similar level. It is used in both groups of products due to its delicate floral scent.

\section{Conclusions}

In the present work selected groups of alcohol-based perfumery products, namely scented waters (eau de parfum) and toilet waters (eau de toilette), were analysed with respect to the content of six out of 26 allergens: linalool, citral, citronellol, geraniol, eugenol and alpha-isomethyl ionone. On the basis of the conducted chromatographic analyses it may be concluded that all the samples (of both toilet waters and scented waters) satisfy the recommendations of the Scientific Committee on Cosmetic Products and Non-food Products for cosmetics intended to remain on the skin for some time, i.e. in the case when the allergen concentration in a product exceeds the value $0.001 \%$, the information confirming its presence in the fragrance composition is given on the cosmetic packaging.

\section{Experimental}

\subsection{General procedure}

Perfumery products are a complex mixture of fragrances of varying volatilities. ${ }^{26}$ The qualitative and quantitative analysis of selected allergens in 50 perfumery products was carried out with the application of a Bruker 430-GC gas chromatograph, with FID detector, equipped with a capillary column VF-1MS $(15 \mathrm{~m} \times 0.25 \mathrm{~mm} \times 0.25 \mu \mathrm{m})$ and an autosampler. A calibration mixture was prepared and on the basis of the obtained chromatograms the positioning of peaks characteristic of the given allergens was determined. On this basis, after integrating the area under the peaks, the content of the analysed substances was determined. The conditions for the analysis: initial temperature of $70^{\circ} \mathrm{C}$ for 12 minutes, heating to $170^{\circ} \mathrm{C}$ - heating rate $5^{\circ} \mathrm{C}$ per minute and maintaining a temperature of $170^{\circ} \mathrm{C}$ for 10 minutes, the flows were $2 \mathrm{~cm}^{3} / \mathrm{min}$. The analyses were performed once for each of the tested samples. Commercially available samples of perfumery products were tested, with the storage time consistent with the information provided on the product labels.

\section{References}

1 Sikora E., Miastkowska M., Wolinska Kennard K., and Lasoń E. (2018) Nanoemulsions as a form of perfumery products. Cosmetics, 5 (4) 63.

2 Teixeira M. A., Rodríguez O., Gomes P., Mata V., and Rodrigues A. (2012) Perfume engineering: design, performance and classification, Butterworth-Heinemann.

3 Brud W. S., and Konopacka- Brud I. (2009) Podstawy perfumerii: historia, pochodzenie i zastosowania substancji zapachowych, Oficyna Wydawnicza MA.

4 Jabłońska- Trypuć A., and Fabiszewski R. (2008) Sensoryka i podstawy perfumerii, MedPharm Polska.

5 Marcus J., Klossek M. L., Touraud D., and Kunz W. (2013) Nano-droplet formation in fragrance tinctures. Flav. Frag. J., 28 (5) 294-299.

6 Public consultation on fragrance allergens in the framework of Regulation (EC) No. 1223/2009 of the European Parliament and of the Council on cosmetic products - Annex.

7 Truchliński J., Sembratowicz I., Gorzel M., and Kiełtyka- Dadasiewicz A. (2015) Allergenic potential of cosmetic ingredients. Arch. Physiother. Glob. Res., 19 (1) 7-15.

8 IFRA (International Fragrance Association), (2019) Guidance for the use of IFRA Standards, December, 2019.

9 Directive 2003/15/EC of the European Parliament and of the Council of 27 February 2003 amending Council Directive 76/768/EEC and the approximation of the laws of the Member States relating to cosmetics products, March, 2003.

10 Lionetti N., and Rigano L. (2018) Labeling of Cosmetic Products. Cosmetics, 5 (1) 22. 
11 Niederer M., Bollhalder R., and Hohl C. (2006) Determination of fragrance allergens in cosmetic by size-exclusion chromatography followed by gas chromatography-mass spectrometry. $J$. Chromatogr. A, 1132 (1-2) 109-116.

12 Letizia C. S., Cocchiara J., Lalko J., and Api A. M. (2003) Fragrance material review on linalool. Food Chem. Toxicol., 41 (7) 943-964.

13 Bickers D., Colow P., Greim H., Hanifin J. M., Rogers A. E., Saurat J. H., Sipes I. G., Smith R. L., and Tagami H. (2003) A toxicologic and dermatologic assessment of linalool and related esters when used as fragrance ingredients. Food Chem. Toxicol., 41 (7) 919-942.

14 IFRA (International Fragrance Association), (2009) Standard on Linalool. $38^{\text {th }}$ Amendment, October, 2009.

15 Rachwalik R. (2015) Technologie otrzymywania wybranych związów zapachowych, Wydawnictwo Politechniki Krakowskiej.

16 IFRA (International Fragrance Association), (2013) Standard on citral. 47 $7^{\text {th }}$ Amendment, June, 2013.

17 Lalko J., and Api A. M. (2008) Citral: Identifying a threshold for induction of dermal sensitization. Regul. Toxicol. Pharmacol., 52 (1) 62-73.

18 IFRA (International Fragrance Association), (2009) Standard on Citronellol. 42 ${ }^{\text {nd }}$ Amendment, October, 2009.

19 Lapczynski A., Bhatia S. P., Letizia C. S., and Api A. M. (2008) Fragrance material review on dlcitronellol. Food Chem. Toxicol., 46 (11) 103-109.

20 Lapczynski A., Bhatia S. P., Foxenberg R. J., Letizia C. S., and Api A. M. (2008) Fragrance material review on geraniol. Food Chem. Toxicol., 46 160-170

21 IFRA (International Fragrance Association), (2009) Standard on Geraniol. 42 ${ }^{\text {nd }}$ Amendment, October, 2009.

22 Nejad S. M., Özgüneş H., and Başaran, N. (2017) Pharmacological and toxicological properties of eugenol. Turk. J. Pharm. Sci., 14 (2) 201-206.

23 Api A. M., Belsito D., Bhatia S., Bruze M., Calow P., Dagli M. L., Dekant W., Fryer A. D., Kromidas L., La Cava S., Lalko J. F., Lapczynski A., Liebler D. C., Miyachi Y., Politano V. T., Ritacco G., Salvito D., Schultz T. W., Shen J., Sipes I. G., Wall B., and Wilcox D. K. (2017) RIFM fragrance ingredient safety assessment, Eugenol, CAS Registry Number 97-53-0. Food Chem. Toxicol., 97 25-37.

24 IFRA (International Fragrance Association), (2009). Standard on Eugenol. 43 ${ }^{\text {rd }}$ Amendment, October, 2009.

25 Lapczynski A., Lalko J., Politano V. T., McGinty D., Bhatia S. P., Letizia C. S., and Api A. M. (2007) Fragrance material review on alpha-iso-methylionone, Food Chem. Toxicol., 45 (1) $280-289$.

26 Zarzo M. (2013) What is a fresh scent in perfumery? Perceptual freshness is correlated with substantivity. Sensors, 13 (1) 463- 483. 


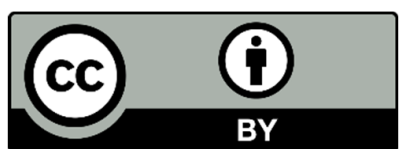

(C) 2021 by the authors; licensee Growing Science, Canada. This is an open access article distributed under the terms and conditions of the Creative Commons Attribution (CC-BY) license (http://creativecommons.org/licenses/by/4.0/). 